\title{
OS REFLEXOS POSITIVOS E NEGATIVOS NA RELAÇÃO DE EMPREGO DIANTE DA NOVA LEI DE TERCEIRIZAÇÃO N 13. 429/2017.
}

\author{
Carlos Eduardo Ferreira Costa ${ }^{1}$ \\ Francine A. Rodante Ferrari Nabhan ${ }^{2}$
}

\section{RESUMO}

As relações de trabalho sofreram mudanças significativas. Dentre tantas criações e mudanças, surgiu o instituto da terceirização, com o intuito de alavancar a economia e melhorar a produtividade. $\mathrm{O}$ fato, é que tal instituto, esta muito presente no cenário empresarial brasileiro, e por isso, faz-se necessário uma análise minuciosa do mesmo. O objetivo deste trabalho é analisar os reflexos da terceirização, buscando identificar os prós e contras decorrentes da relação frente aos danos causados ao trabalhador terceirizado. Trata-se de uma pesquisa exploratória, bibliográfica e com método de abordagem dedutivo.

Palavras-Chave: Reforma Trabalhista; Reflexos; Terceirização; Trabalho; Dano.

\section{THE POSITIVE and NEGATIVE REFLEXES in the EMPLOYMENT RELATIONSHIP with THE NEW OUTSOURCING LAW No. 13. 429/2017.}

\begin{abstract}
Labor relations have undergone significant changes. Among many creations and changes, the outsourcing institute emerged, with the aim of leveraging the economy and improving productivity. The fact is that such an institute is very present in the Brazilian business scenario, and therefore, it is necessary to have a thorough analysis of it. The objective of this work is to analyze the reflections of outsourcing, seeking to identify the pros and cons arising from the relationship against the damage caused to the outsourced worker. This is an exploratory and bibliographic research with a method of deductive approach.method.
\end{abstract}

Keywords: Labor reform; Reflexes; Outsourcing; Work; Damage.

\section{INTRODUÇÃO}

No Brasil, e em grande parte dos países ocidentais, é possível observar um esforço por parte do governo em reduzir a intervenção estatal no setor produtivo. Dessa forma, o Direito

\footnotetext{
${ }^{1}$ Doutorando em Direito pela Faculdade Autônoma de Direito - FADISP (2018), Mestre em Desenvolvimento Regional - UNIALFA (2015/2017), Pós - Graduado em Direito Público - UNICAM, ex- Coordenador do Curso de Direito da Faculdade do Maranhão situada em São Luís/MA. Atualmente é docente na Universidade Federal do Maranhão - UFMA (campus Imperatriz), FACIMP/WYDEN e Unisulma.. E-mail: c.educosta@ live.com ${ }^{2}$ Mestre em Gestão e Desenvolvimento Regional - Universidade de Taubaté - UNITAU (2016), Especialista em Direito e Processo do Trabalho pela UNITEC (2014), Especialista em Direito Civil pela UNISUL(2007). Pesquisadora do Núcleo de Pesquisas Jurídicas de Imperatriz - Democracia e Direitos Fundamentais (NUPEJI). Advogada. Professora do Curso de graduação em Direito da UNISULMA/IESMA e FACIMP/WYDEN. E-mail: francinenabhan@hotmail.com
} 
do Trabalho tem sofrido, nos dias atuais, profundas mudanças, sendo especialmente relevante a tendência de flexibilização das relações de trabalho, as quais seriam capazes de assegurar a manutenção do emprego e retirar milhões de trabalhadores do mercado informal, sem carteira assinada, sem quaisquer direitos.

No âmbito do Direito do Trabalho, a terceirização surge como um fenômeno por meio do qual a relação econômica de trabalho justrabalhista encontra-se dissociada do que lhe seria correspondente a partir da qual o trabalhador é inserido no processo produtivo.

Consagra a Constituição Federal o direito à segurança no emprego, de modo que protege a relação de emprego contra despedida arbitrária ou sem justa causa, tendo em vista que o trabalho consiste em relevante interesse social para melhoria da qualidade de vida.

Em quase todos os países, tem-se observado a terceirização como um fenômeno que se apresenta com maior ou menor intensidade, gerando novos empregos e novas empresas para o exercício da atividade em que se aprimoram, delegando a terceiros a execução de alguns serviços.

Antes da Reforma Trabalhista, a terceirização era aplicada com muita cautela no Brasil, pois existiam muitas restrições à prática da mesma, como por exemplo, a proibição da terceirização para atividades-fim. Isso significava quesomente as atividades-meio realizadas em uma empresa poderiam ser terceirizadas. Após a Reforma, isso mudou, e atualmente, as empresas possuem a liberdade de utilizar a terceirização para qualquer função, permitindo que praticamente todos os seus funcionários sejam terceirizados. Por isso, pode-se afirmar que com a Reforma, ocorreu o processo de precarização do trabalho.

Mesmo com a CRFB/88 formulada de acordo com o princípio da dignidade da pessoa humana e reconhecendo a proteção do trabalho digno como direito fundamental, a realidade atual no mercado de trabalho é outra. Onde, as empresas sempre buscam reduzir seus custos de produção e aumentar o seu faturamento.

$\mathrm{Na}$ análise jurídica do fenômeno da terceirização, percebe-se que esse mecanismo tem sido uns dos principais responsáveis pela precarização do trabalho, deixando o empregado ainda mais submisso ao empregador.

Este trabalho tem como objetivo analisar o instituto da terceirização no ordenamento jurídico brasileiro, averiguando se tal modalidade de contratação assegura um trabalho digno e humanístico ao trabalhador. 
Para a realização deste trabalho, primeiramente busca-se analisar a regulamentação da terceirização no Brasil, onde apresenta-sea origem, a evolução, o conceito de terceirização e, por fim, analisamos a Lei $\mathrm{n}^{\circ} 13.429 / 2017$, a Nova Lei da Terceirização.Por fim, passa-se a analisar se o instituto da Terceirização causou a flexibilização ou a precarização dos direitos trabalhistas, e a consequiência disso para o trabalhador. Nesta parte do trabalho, busca-se analisar os efeitos da terceirização, destacando seus prós e contras ao trabalhador e empregador, o dano existencial que está contido na terceirização e, por fim, resgatamos a necessidade de proteção ao trabalhador terceirizado.

Quanto a metodologia, destaca-se que trata-se de uma pesquisa exploratória onde busca-se demonstrar de forma explícita e clara os danos sofridos pelo trabalhador terceirizado. O procedimento utilizado é o bibliográficoe quanto ao seu método de abordagem é o dedutivo.

Dessa forma, verifica-se que a terceirização é usada como precursora de um Direito do Trabalho flexível, mas que, em alguns momentos, esta sendo utilizada de maneira errônea conforme busca-se demonstrar no presente trabalho.

\section{A REGULAMENTAÇÃO DA TERCEIRIZAÇÃO NO BRASIL}

O Direito do Trabalho no Brasil sofreu influências tanto do contexto histórico mundial quanto da sua forma de colonização. O que deu origem a conquistas tardias se comparada a outros países, como ocorreu nos casos do fim da escravidão e na implantação de indústrias.

A primeira Constituição Brasileira a tratar do Direito Trabalhista foi a de 1934, que passou a garantir o salário mínimo, jornada de trabalho de oito horas por dia, isonomia salarial, liberdade sindical, repouso semanal, férias, entre outros direitos. Destaca Silva Neto (2006) que “a Constituição de 1934 é um marco na evolução histórica de nosso direito constitucional, garantido e inscrevendo os direitos sociais, incorporando o sentido social do direito e ampliando os horizontes do direito social à família, à educação e à saúde.”.

Em 1943 foi sancionada a Consolidação das Leis Trabalhistas (CLT). Seu principal objetivo era a regulamentação das relações individuais e coletivas do trabalho. Abordando, tanto o trabalho urbano quanto o rural. De 1943 até os dias atuais, a CLT sofreu alterações 
conforme evolução da sociedade e principalmente das relações de emprego. Alterações essas que atingem diretamente o Direito do Trabalho e Direito Processual do Trabalho. Apesar das mudanças, a CLT continua sendo o principal meio que regulamenta as relações de trabalho e protege os trabalhadores.

Mais especificamente quanto a terceirização, destaca-se quea mesma originou-se na Segunda Guerra Mundial, onde empresas dos Estados Unidos precisaram concentrar-se na produção de armamentos. Com essa finalidade, elas passaram a focar na atividade principal e delegaram as atividades secundárias a empresas prestadoras de serviços, melhorando a produção da empresa e a forma operacional da mesma. O resultado disso foi nomeado outsourcing, no português, terceirização.

Com o passar dos anos, mais precisamente na década de 1980, com o processo de internacionalização das empresas multinacionais, o conceito de terceirização passou a ser destrinchado, e a sua forma e seus objetivos também. Logo, mudanças significativas nas empresas foram acontecendo, não sendo diferente no Brasil. Esse processo de terceirização no Brasil ocorreu de forma gradativa.

Em 2017, foi aprovada a Lei $\mathrm{N}^{\circ}$ 13.467/2017, mais conhecida como Reforma Trabalhista.

Segundo o posicionamento de Biavaschi, Coelho, Droppa ePernías (2018, p. 213):

\begin{abstract}
A reforma brasileira, introduzida por lei infraconstitucional (Lei 13.467/2017), trouxe como uma das justificativas a busca da "segurança jurídica" na medida em que, segundo seus defensores, a excessiva judicialização dos conflitos e a atuação da justiça do Trabalho em dissintonia com a "modernidade" estariam a gerar inseguranças e a afastar os investimentos necessários ao desenvolvimento. Daí porque vários dos dispositivos da lei da reforma, de forma direta ou indireta dirigem-se a reduzir o papel da justiça do Trabalho, e a limitar seus espaços de atuação. E o fazem, quer restringindo as vias de acesso ao judiciário Trabalhista, ao impor ônus às reclamações; quer reduzindo as atribuições dessa instituição e as possibilidades interpretativas de seus magistrados; quer transtrocando as fontes do Direito do Trabalho para além da lei universal e, mesmo, em determinados aspectos, para além do negociado coletivamente. Ao definir como prevalente a norma individual produzida no "livre" encontro das vontades de empregados e empregadores, a reforma participa de um movimento regressivo que viola os princípios do Direito do Trabalho, os constitucionais (Constituição de 1988) e os tratados e convenções internacionais.
\end{abstract}

O objetivo principal da Reforma era a flexibilidade, onde empregado e empregador passaram a ter liberdade de se ajustarem de acordo com as necessidades do trabalho. 
Segundo Romar (2018, p. 182):

Há, no conjunto da Lei $N^{\circ} 13.467 / 2017$, uma lógica que busca diminuir, no marco do direito do trabalho no Brasil, a noção de que a venda da mercadoria força de trabalho trata-se de uma relação entre pessoas, substituindo-a por uma visão que trata essa venda como uma relação entre coisas.

A essência da reforma trabalhista está no livre encontro das vontades individuais dos empregados e empregadores que, segundo destaca Biavaschi (2017) "espaço sem obstáculos ao seu livre trânsito, produzem normas que regerão harmonicamente as relações entre compradores e vendedores da força de trabalho...”, observando como na teoria deveria ser, e analisando como ocorre na prática.

Em 2017, foi aprovada também a lei da terceirização, instituto que passa a ser analisado diretamente no tópico seguinte.

\section{TERCEIRIZAÇÃO}

A palavra terceiro tem origem no latim tertius, que significa "aquele que é estranho a uma relação jurídica entre outras pessoas". O que leva a crer na superveniência de uma ação de terceiro através da delegação de partes concentradas em um contrato é permitido conforme o consenso dos atores envolvidos no vinculo contratual que os legitimam para tanto.

\subsection{CONCEITO}

Terceirização é a contratação de serviços por meio de uma empresa intermediária, interposta entre o tomador de serviços e a mão-de-obramediante o contrato de prestação de serviços. Vale ressaltar que ela constitui o fornecimento de atividade especializada, e não simplesmente o fornecimento de trabalhadores.

A relação de emprego se dá entre o trabalhador e a empresa prestadora de serviços e não diretamente com o contratante, tendo como objetivo principal a contratação de terceiros 
para realização do serviço laborativo, obtendo ganho de qualidade, eficiência, especialização, eficácia, produtividade da atividade principal da empresa, racionalização de custos, a economia de recursos e a desburocratização administrativa.

É importante destacar que as atividades terceirizadas são para atividades gerais e não essenciais da empresa, dessa forma, permite que esta concentre-se na sua atividade principal.Castro (2000, p.78) conceitua a terceirização como sendo:

[...] o vocábulo utilizado para designar uma moderna técnica de administração de empresas que visa ao fomento da competitividade empresarial através da distribuição de atividades acessórias a empresas especializadas nessas atividades, a fim de que possam concentrar-se no planejamento, na organização, no controle, na coordenação e na direção da atividade principal.

Já Barros (2009, p.446):

O fenômeno da terceirização consiste em transferir para outrem atividades consideradas secundárias, ou seja, de suporte, atendo-se a empresa à sua atividade principal. Assim, a empresa se concentra na sua atividade-fim, transferindo as atividades-meio.

Como destaca Robortella(2009) "a palavra terceirização indica a existência de um terceiro que, com competência, especialidade e qualidade, em condição de parceria, presta serviços ou produz bens para uma empresa contratante."

Pode-se destacar que o fenômeno da terceirização é abrangente, amplo e com múltiplas possibilidades de aplicação.

\subsection{EVOLUÇÃO LEGISLATIVA}

Os dispositivos que abordam a terceirização no ordenamento jurídico brasileiro não são numerosos, visto que ainda vem sendo aprimorado e adaptado conforme as necessidades do empregado e empregador. Observa-se evolução significativa no que se refere a sua aplicabilidade, já que antes havia uma insuficiência às normas que disciplinassem tal matéria.

O Decreto-Lei n ${ }^{\circ}$ 200, de 1967 com a Lei no 5.645/1970 e Lei nº 6.019/74 possibilitou que a Administração Pública realizasse algumas das suas atividades com a participação de terceiros. É tido ainda hoje como um marco legislativo a respeito de contratação terceirizada na área pública. 
Outro dispositivo importante foi a Lei $\mathrm{n}^{\mathrm{o}} 7.102$ de 1983 , que passou a admitir a terceirização em serviços de vigilância e de transporte de dinheiro. É válido destacar que a Lei foi a primeira a tratar da contratação de serviços entre empresas.

Dessa forma, as poucas alterações feitas tornam-se relevantes, como a Súmula nº331 do Tribunal Superior do Trabalho (TST) publicada em 31.05.2011onde dispõe que:

Súmula $n^{\circ} 331$ do TST.CONTRATO DE PRESTAÇÃO DE SERVIÇOS. LEGALIDADE (nova redação do item IV e inseridos os itens V e VI à redação) - Res. 174/2011, DEJT divulgado em 27, 30 e 31.05.2011.

I-A contratação de trabalhadores por empresa interposta é ilegal, formandose o vínculo diretamente com o tomador dos serviços, salvo no caso de trabalho temporário (Lei $\mathrm{n}^{\mathrm{o}}$ 6.019, de 03.01.1974). II-A contratação irregular de trabalhador, mediante empresa interposta, não gera vínculo de emprego com os órgãos da Administração Pública direta, indireta ou fundacional (art. 37, II, da CF/1988). III-Não forma vínculo de emprego com o tomador a contratação de serviços de vigilância (Lei $n^{\circ} 7.102$, de 20.06.1983) e de conservação e limpeza, bem como a de serviços especializados ligados à atividade-meio do tomador, desde que inexistente a pessoalidade e a subordinação direta.

IV-O inadimplemento das obrigações trabalhistas, por parte do empregador, implica a responsabilidade subsidiária do tomador dos serviços quanto àquelas obrigações, desde que haja participado da relação processual e conste também do título executivo judicial. V-Os entes integrantes da Administração Pública direta e indireta respondem subsidiariamente, nas mesmas condições do item IV, caso evidenciado a sua conduta culposa no cumprimento das obrigações da Lei n. $^{\circ}$ 8.666, de 21.06.1993, especialmente na fiscalização do cumprimento das obrigações contratuais e legais da prestadora de serviço como empregadora. A aludida responsabilidade não decorre de mero inadimplemento das obrigações trabalhistas assumidas pela empresa regularmente contratada. VI - A responsabilidade subsidiária do tomador de serviços abrange todas as verbas decorrentes da condenação referentes ao período da prestação laboral.

Desse modo, pontua Viana, Delgado e Amorim (2011, p.60):

A Súmula n³31 do TST traça limites jurídicos à terceirização - o que a torna duplamente importante, seja para o bem como para o mal. Para o bem, porque - em razão dos próprios limites - ajuda a conter o fenômeno. Para o mal, porque - dentro dos mesmos limites - ela o legitima e reforça.

Vale frisar que a Súmula $n^{\circ} 331$ do TST vem editada sob a Súmula n²56 do TST (cancelada), que determinava:

CONTRATO DE PRESTAÇÃO DE SERVIÇOS. LEGALIDADE. (cancelada) - Res. 121/2003, DJ 19, 20 e 21.11.2003.

Salvo os casos de trabalho temporário e de serviço de vigilância, previstos nas Leis $\mathrm{n}^{\circ} \mathrm{s}$ 6.019, de 03.01.1974 e 7.102, de 0.06.1983, é ilegal a 
contratação de trabalhadores por empresa interposta, formando-se o vínculo empregatício diretamente com o tomador dos serviços.

O Enunciado acima foi aplicado de forma restrita, tendo sua interpretação ampliada graças a Súmula nº331 do TST, nesse sentido observa-se que ocorrem limitações quanto aos serviços que podem ser terceirizados. Trazendo um limite legal à terceirização.

Com a edição da Súmula foi expandida a terceirização, onde até então era restrita aos entes da Administração Pública Direta ou no setor privado como dito acima em serviços de vigilância e transporte de dinheiro.

Com essa mudança, a terceirização passou a ser admitida além dos casos anteriormente previstos, em serviços de conservação e limpeza, além de qualquer outro caso, desde que não esteja ligado à atividade-fim, só atividade-meio.

Ademais, conforme dispõe Cassar (2016) "a maioria dos trabalhadores terceirizados e subcontratados são verdadeiros empregados das empresas tomadoras, disfarçados por contratos simulados com cooperativas, associações ou empresas oportunistas.” Destacando o que Sussekind (2013, p.275) assevera que:

Ainda que os contratos previstos no Código Civil hajam sido celebrados para tarefas estranhas às atividades normais a empresa contratante, caberá verificar-se, em cada caso, se os empregados da firma contratada trabalham, de fato, subordinados ao poder de comando da referida empresa. Em caso afirmativo, haverá nítida simulação em fraude à lei trabalhista (art. $9^{\circ}$ da CLT), configurando-se o contrato realidade de trabalho entre a empresa contratante e os trabalhadores formalmente vinculados à firma contratada (art. 442, combinado com os arts. $2^{\circ}$ e $3^{\circ}$ da CLT).

Ainda, conforme Cassar (2018, p.482):

Isto se explica porque a intermediação de mão de obra fere de morte os princípios: da proteção ao empregado; da norma mais favorável; da condição mais benéfica; do tratamento isonômico entre os trabalhadores que prestam serviço a mesmo enquadramento legal etc. Isso porque os empregados terceirizados possuem direitos inferiores e diversos dos empregados do tomador de serviço.

O uso de mão-de-obra ilimitada de trabalhadores terceirizados fere a própria ordem constitucional, desprezando o valor social do trabalho e trabalhador; e deixando de lado a intensa busca na melhoria das condições de trabalho.

É nesse sentido que o Ministério do Trabalho, no uso das atribuições legais que lhe confere o inciso VI, do art. 87 da CRFB/88, considerando a necessidade de uniformizar o procedimento de Fiscalização do Trabalho, elaborou a Instrução Normativa $n^{\circ} 03$ de $1^{\circ}$ de 
setembro de 1997, a fim de inibir o abuso da terceirização e a fraude no contrato de trabalho. (IN n $3 / 97)$

Diante da análise jurídica do fenômeno da terceirização, percebe-se que esse mecanismo tem sido um dos principais responsáveis pela precarização do trabalho, causando vários danos ao empregado terceirizado. Portanto, torna-se essencial analisar a nova legislação referente a referido instituto.

\subsection{LEI Nº13. 429/2017: NOVA LEI DA TERCEIRIZAÇÃO}

A Lei nº13. 429/2017, conhecida como a Lei da Terceirização, é uma lei brasileira sancionada no dia 31 de março de 2017, alterando dispositivos da Lei nº. 019 de 3 de janeiro de 1974, que dispõe sobre o trabalho temporário nas empresas urbanas e dá outras providências, e dispõe também sobre as relações de trabalho na empresa de prestação de serviços a terceiros.

Desde a sua aprovação, a lei gerou muitas discussões e controvérsias. A mesma trouxe significativas mudanças para as relações de emprego, regulamentando essa forma de contratação.

Vale ressaltar que, a terceirização trabalhista não era regulamentada de forma objetiva e clara pela legislação brasileira. Como já destacado, a Súmula n³31 do TST era até então “o norte" da terceirização.

Pela Súmula, considerava-se lícita a terceirização da atividade-meio da empresa, como por exemplo, os serviços de conservação, limpeza, vigilância. Logo, se envolvesse a atividade-fim, a terceirização era considerada ilícita.

Em relação ao tema, Delgado (2016) difere a atividade-fim da atividade-meio pelo fato de a primeira tratar de funções e tarefas voltadas ao núcleo da dinâmica da empresa. Dessa forma, compõe sua essência e a posiciona e classifica no contexto empresarial e econômico. São as atividades que configuram seu núcleo e definem sua essência. A segunda, por sua vez, são as atividades empresariais periféricas, ou seja, não se enquadram como seu núcleo nem compõem sua essência. Assim, diferentemente do que ocorre com as atividades finais, essas não serão relevantes para o seu posicionamento no contexto empresarial. 
Essa é a mudança principal trazida pela lei, onde, qualquer atividade da empresa poderá ser terceirizada. Na qual a restrição existente em relação ao exercício de atividade-fim deixa de valer.

Entre outras alterações trazidas pela lei, há mudança nos contratos temporários, onde antes,sua duração não poderia ser superior a 90 dias. Agora o prazo é de 180 dias podendo ser prorrogado por mais 90 dias, se justificado de forma devida. Como demonstra o art. 10 da lei:

Art. 10.Qualquer que seja o ramo da empresa tomadora de serviços, não existe vínculo de emprego entre ela e os trabalhadores contratados pelas empresas de trabalho temporário.

$\S 1^{\circ} \mathrm{O}$ contrato de trabalho temporário, com relação ao mesmo empregador, não poderá exceder ao prazo de cento e oitenta dias, consecutivos ou não.

$\S 2^{\circ} \mathrm{O}$ contrato poderá ser prorrogado por até noventa dias, consecutivos ou não, além do prazo estabelecido no $\S 1^{\circ}$ deste artigo, quando comprovada a manutenção das condições que o ensejaram.

A Lei também determina que a empresa terceirizada é a responsável pela contratação dos funcionários e pela remuneração do trabalho dos mesmos. No contrato deverá constar especificadamente o serviço prestado. Já a responsabilidade da empresa tomadora dos serviços será subsidiária, portanto, no caso de não pagamento de salário ou outros problemas, o trabalhador deve recorrer seus direitos junto à prestadora de serviços e somente em último caso, recorrer à empresa tomadora do serviço.

De acordo com a lei da terceirização, a empresa que contrata os terceirizados deve garantir condições de saúde e segurança ao trabalhador, conforme seu art. $9^{\circ}$, incisos e parágrafos:

Art. $9^{\circ} \mathrm{O}$ contrato celebrado pela empresa de trabalho temporário e a tomadora de serviços será por escrito, ficará à disposição da autoridade fiscalizadora no estabelecimento da tomadora de serviços e conterá:

I - qualificação das partes;

II - motivo justificador da demanda de trabalho temporário;

III - prazo da prestação de serviços;

IV - valor da prestação de serviços;

V - disposições sobre a segurança e a saúde do trabalhador, independentemente do local de realização do trabalho.

$\S 1^{\circ}$ É responsabilidade da empresa contratante garantir as condições de segurança, higiene e salubridade dos trabalhadores, quando o trabalho for realizado em suas dependências ou em local por ela designado.

$\S 2^{\circ}$ A contratante estenderá ao trabalhador da empresa de trabalho temporário o mesmo atendimento médico, ambulatorial e de refeição destinado aos seus empregados, existente nas dependências da contratante, ou local por ela designado.

$\S 3^{\circ} \mathrm{O}$ contrato de trabalho temporário pode versar sobre o desenvolvimento de atividades-meio e atividades-fim a serem executadas na empresa tomadora de serviços. 
Nesse paralelo, destaca-se que o trabalhador terceirizado terá todos os seus direitos mantidos como: $13^{\circ}$ salário, pagamento de horas extras, recolhimento do FGTS e todos os demais direitos previstos na CLT. A mudança e limitação ocorrem em relação aos direitos previstos nas convenções ou acordos coletivos, que não serão aplicáveis a esses terceirizados. Nesses casos, sempre caberá à empresa optar por estender esses direitos aos terceirizados.

Antes da Lei $n^{o}$ 13.429/2017, não havia regulamentação sobre as empresas que poderiam oferecer esse tipo de serviço. Entretanto, agora as empresas que desejarem trabalhar com a terceirização de serviços deverão comprovar conforme art. $4^{\circ} \mathrm{B}$ acrescido na Lei no6.019/74:

Art. $4^{\circ}$-B. São requisitos para o funcionamento da empresa de prestação de serviços a terceiros:

I - prova de inscrição no Cadastro Nacional da Pessoa Jurídica (CNPJ);

II - registro na Junta Comercial;

III - capital social compatível com o número de empregados, observando-se os seguintes parâmetros:

a) empresas com até dez empregados - capital mínimo de $\mathrm{R} \$$ 10.000,00 (dez mil reais);

b) empresas com mais de dez e até vinte empregados - capital mínimo de $\mathrm{R} \$$ 25.000,00 (vinte e cinco mil reais);

c) empresas com mais de vinte e até cinquenta empregados - capital mínimo de $\mathrm{R} \$ 45.000,00$ (quarenta e cinco mil reais);

d) empresas com mais de cinquenta e até cem empregados - capital mínimo de $\mathrm{R} \$ 100.000,00$ (cem mil reais); e

e) empresas com mais de cem empregados - capital mínimo de $\mathrm{R} \$$ 250.000,00 (duzentos e cinquenta mil reais).

Nesse passo, constata-se que a nova lei da terceirização passa a trazer segurança jurídica aos trabalhadores e as empresas. Deixando impactos com seus prós e contras; e vantagens e desvantagens.

\section{TERCEIRIZAÇÃO: FLEXIBILIZAÇÃO E PRECARIZAÇÃO}

A flexibilidade nas relações trabalhistas traz, no ponto de vista social, certa vulnerabilidade ao trabalhador, principalmente no que tange a terceirização. É por meio dela que o processo produtivo é flexibilizado, já que ocorre uma reestruturação nas atividades empresariais. Conforme dispõe Paixão (2006, p. 9): 
Um dos desdobramentos mais perversos da expansão da terceirização está na seguinte conclusão: o trabalhador terceirizado é um indivíduo sem referência de tempo e espaço - que são as dimensões constitutivas da experiência humana no mundo exterior.

Ainda segundo Paixão (2006, p. 9):

[...] para o trabalhador terceirizado, a insegurança e o temor são maiores: ele não tem perspectiva de ascensão funcional; a competitividade entre as empresas tem como consequência a busca de um trabalhador barato, sem experiência, sem treinamentos, sem expectativas; a perspectiva de planejamento do futuro é subtraída do trabalhador terceirizado, já que a possibilidade de ascensão profissional e qualificação são ínfimas.

O trabalhador terceirizado, mais do que outro trabalhador, tem a perspectiva de planejamento para o futuro afetado. Porque, via de regra, não há interesse na qualificação de sua mão-de-obra. Qualificação significa aumento de salário. Vale deixar claro que o terceirizado não possui segurança, visto que seu emprego é algo incerto.

A OIT (Organização Internacional do Trabalho), através de seus objetivos e por meio de seus instrumentos normativos e mecanismos de controle, busca assegurar a efetivação dos direitos fundamentais trabalhistas a partir dos preceitos de dignidade, liberdade e igualdade.

Sabe-se que a inadimplência trabalhista é um dos principais problemas vivenciados pelos trabalhadores terceirizados.Com isso, é importante ater-se ao que é do homem por direito. Os direito e deveres fundamentais previstos na Constituição Federal, como pondera Porto (2013, p. 82):

As reflexões sobre a garantia constitucional do pleno emprego precisam se vincular às demandas advindas das relações precárias ou rompidas com o mundo assalariado. A plenitude não deve significar, de forma simplificada, apenas a disponibilidade quantitativa de ocupações para as pessoas que vivem do trabalho, mas sim a oferta de trabalho protegido, num contexto de dignidade $[\ldots]$

São diversos os efeitos negativos para o trabalhador. A terceirização surge como forma de precarizar e terceirizar o trabalho, desconfigurando a relação de emprego clássica.

\subsection{OS EFEITOS DA TERCEIRIZAÇÃO}


Como dito anteriormente, a terceirização possui seus prós e contras.Para alguns a lei facilita a geração de empregos, visto que, diminui as atividades prestadas na modalidade terceirizada de forma irregular e passa a estimular a contratação de empregos formais.

A lei vem trazendo inúmeras vantagens às grandes empresas. Dentre alguns desses benefícios vale destacar:a diminuição de custos; o aumento do faturamento; a redução no quadro de funcionários, ocasionando menos encargos trabalhistas. Ela acaba reduzindo os custos para as empresas porque diminui os encargos trabalhistas e contempla com uma grande economia na folha de pagamento.

Há quem defenda que a terceirização influencia numa maior qualificação profissional, visto que, os funcionários vêm de uma empresa especializada que fornece determinado serviço, fazendo com que o grau de qualificação aumente e consequentemente melhorando a qualidade do serviço prestado.

Ocorre também um maior leque de opções do serviço que busca ser prestado. A empresa $\mathrm{X}$ já procura no mercado de trabalho empresas específicas para aquela área de prestação de serviço, originando uma maior "pechincha" e dando ao contratante a melhor relação custo-benefício.

Enquanto para uns a terceirização traz tantos benefícios, para outros só prejuízos. Nesse contexto os mais afetados são os trabalhadores. Os efeitos negativos provocados pelo mau uso do instituto da terceirização são muitos.

Os salários do trabalhador terceirizado são em média $20 \%$ a $25 \%$ mais baixos se comparado a um trabalhador não terceirizado em sua mesma função. A justificativa para isso é que, se a empresa reduz custos ao terceirizar seus serviços, a empresa contratada automaticamente também diminui seus salários em busca de um maior lucro.

O fato de o empregado terceirizado não possuir recursos para pagar especializações em cursos profissionalizantes, acaba atingindo financeiramente todas as áreas de sua vida, impedindo de certa forma, que ele se organize financeiramente e deixe de concretizar alguns de seus sonhos e objetivos do futuro.

Outro grande malefício ao trabalhador são os enfraquecimentos dos sindicatos, fazendo com que perca benefícios conquistados pelo setor. É perceptível que numa visão empresarial e social, uma representatividade sindical tenha mais força e poder que um funcionário sem esse amparo e respaldo sindical. 
A alta rotatividade aos terceirizados e a intermitência desses empregos prejudicam o contínuo levantamento de depósito do FGTS, reduzindo a capacidade de poupança do trabalhador terceirizado, além de reduzir o tempo de serviço proporcional do aviso prévio.

O fato de o terceirizado ter sua remuneração diminuída incide também de forma negativa sobre todos os seus direitos, como férias, décimo terceiro, adicionais, e etc., precarizando sua condição social.

Reflete na terceirização uma menor estabilidade e segurança empresarial, porque empresas menores e novas são mais instáveis o que acaba aumentando o risco de perda do emprego e demissões em massa; ou empresas ocorrerem riscos de não darem certo e acabar fechando suas portas.

Estatisticamente, os números de acidentes de trabalho, de adoecimento profissional e doenças ocupacionais no ambiente de trabalho tendem a serem maiores em trabalhadores terceirizados. Essas doenças representam não só um dano à saúde, mas como também um dano à própria existência do trabalhador.

Caso em que há a perda de um membro, ou uma L.E.R. (lesão por esforço repetitivo), por exemplo, o trabalhador tem sua rotina afetada não só nas atividades profissionais, mas como também na prática de atividades comuns do dia-a-dia.

No ponto de vista de Pereira (2018):

A análise científica do fenômeno da terceirização demonstra que esse mecanismo de gestão tem sido responsável por arquitetar empresas vazias de sentido social e de direitos fundamentais. Tais empresas, portanto, não passam de embalagem oca.

Dessa forma, podemos concluir que a terceirização é usada como precursora de um Direito do Trabalho flexível e favorável às empresas e ao trabalhador, quando na verdade nada mais é do que uma estratégia para enfraquecer e reduzir os direitos e garantias conquistados ao longo dos anos de muita luta.

\subsection{O DANO EXISTENCIAL}

De modo geral, de acordo com Romar (2018, p. 196):

O dano existencial, em seu aspecto objetivo, consiste na lesão ao complexo de relações que auxiliam no desenvolvimento normal da personalidade do 
sujeito, abrangendo tanto a ordem pessoal, como a ordem social. É uma afetação negativa de atividade ou conjuntos de atividades que a vítima realizava em seu cotidiano e que, em razão do efeito lesivo, precisou modificar ou mesmo suprimir de sua rotina.

Nesse sentido, podemos afirmar que não apenas o dano existencial contido na terceirização que afeta a vida nas relações trabalhistas, mas como também qualquer direito fundamental que seja violado e acabe interferindo nas atividades executas pelo indivíduo.

Dessa forma, pode-se dizer que o dano existencial afeta todas as atividades cotidianas do homem, impedindo de certa forma o seu convívio familiar e social. Diante disso causa uma frustração nos sonhos e objetivos escolhidos e idealizados pelo indivíduo, ofendendo a dignidade da pessoa humana.

Para Delgado (2016, p.122),

A terceirização de atividade-fim afronta o sistema constitucional de proteção à pessoa humana que vive do trabalho protegido, ferindo a própria estruturação de um Estado Democrático de Direito fundado na pessoa humana, em sua dignidade, na valorização do trabalho, na justiça social e na subordinação da propriedade à sua função socioambiental.

Os períodos de descanso nas relações de trabalho terceirizadas muitas vezes não são respeitados, afetando o tempo do trabalhador destinado à vida de relações bem como desrespeitados os intervalos, afetando o convício com familiares e amigos.

Vale destacar que a alta rotatividade da mão de obra faz com que o terceirizado emende um contrato de trabalho no outro, sem gozar de férias. Conforme pontuam Alvarenga e Filho (2013, p.250):

É preciso, contudo, ressaltar, e de forma enfática, que não é apenas a inadimplênciadas parcelas correspondentes à sobrejornada que torna o seu usoindiscriminadoe abusivo, comouma estratégia gerencial, ummal parao empregado.Ainda que ashorassuplementaressejamcorretamentequitadas,oprejuízoqueessapolíticaca usa aotrabalhador,impedindo-odedesfrutardoconvíviocom seusamigos,fazendo-

lheperderaoportunidadedeverseusfilhoscrescerem, porvezes, privandooatémesmododireitodeexercerseucredoreligioso,subsistirá.Épossívelperceber prejuízoaodesfrutepelotrabalhadordosprazeresdesuaprópriaexistênciatantoqu andodeleseexigea

realizaçãodehorasextrasemtemposuperioraodeterminadopelaleicomoquandod eleseexige umnúmerotãograndedeatribuiçõesqueprecisepermanecerem atividade duranteseusperíodosdedescanso.

Diante disso, ao originar um sacrifício nas atividades do indivíduo para cumprir metas, ou submeter-se às circunstâncias indignas para não perder o emprego, o dano existencial afeta 
fortemente o trabalhador que antes de ser trabalhador é humano, influenciando em mudanças e afetando sua vida.

No que diz respeito à insegurança no trabalho terceirizado, Viana (2010, p.484) destaca:

Às vezes, como num filme, ele pode nos fazer lembrar o passageiro de uma máquina do tempo. A qualquer momento, no futuro, pode ser remetido ao ponto de partida, e ter de recomeçar ainda e sempre, talvez em outra cidade, talvez de outro modo, em geral com mais sofrimento. A nova empresa exige dele um vínculo forte, mas em troca lhe oferece um vínculo frágil.

Merece destaque também o dano existente em alguns trabalhos com condições degradantes ou análogas à de escravo. Conforme já dito, o trabalhador para manter-se no emprego, presta-se a condições desumanas. As maiores incidências de casos assim são de trabalhadores terceirizados. Nesses casos, o empregador coage o empregado a realizar tarefas em condições precárias, ou relação às condições de higiene do local, ou até mesmo há horários de trabalhos exorbitantes.

Diante disso, é certo afirmar que a terceirização configura dano existencial na vida do trabalhador, na medida em que influencia e contribui na precarização das condições de trabalho e viola os direitos fundamentais do homem e do trabalhador.

\subsection{A NECESSIDADE DE RESGATE DA PROTEÇÃO AO TRABALHADOR}

O homem merece não só um trabalho digno, mas uma vida digna também. A dignidade da pessoa humana é prevista na $\mathrm{CRFB} / 88$, no art. $1^{\circ}$, inciso III e consiste em valor soberano, supremo e fundamental em todo o ordenamento jurídico.

Compreender a dignidade da pessoa humana significa compreender os direitos fundamentais e humanos. Para Delgado (2016, p.79):

O que se percebe, em última análise, é que onde não houver respeito pela vida e pela integridade física e moral do ser humano, onde as condições mínimas para uma existência digna não forem asseguradas, onde não houver limitação do poder, enfim, onde a liberdade e a autonomia, a igualdade (em direitos e dignidade) e os direitos fundamentais não forem reconhecidos e minimamente assegurados, não haverá espaço para a dignidade da pessoa humana e esta (a pessoa), por sua vez, poderá não passar de mero objeto de arbítrio e injustiças. 
A CRFB/88 aplica o princípio da dignidade da pessoa humana de forma ampla, fugindo daquele caráter meramente normativo e partindo de que tudo aquilo que fere o homem e sua integridade (física, moral, social) fere também sua dignidade.

Ainda no âmbito da Constituição, os direitos sociais e principalmente os direitos trabalhistas, assumem importante relevância por incluir o homem na sociedade. Desse modo, o trabalho é valorizado e passa a ser dotado de valor social e econômico.

Importante destacar que não existe democracia plena sem trabalho digno e sem o respeito à pessoa humana e aos trabalhadores. Partindo disso que, a ordem constitucional não limitou-se a prever direitos, mas colocou em prática diversas garantias e meios para efetiválos.

$\mathrm{Na}$ terceirização em si, o trabalhador terceirizado não é acolhido pelo sistema de proteção jurídica e trabalhista adequada, porque na prática, mesmo ele recebendo as parcelas trabalhistas decorrentes da relação empregatícia, ele é condicionado a vários aspectos prejudiciais, como já analisados, onde não há melhores salários, não há um anseio de progresso, seus direitos e garantias não são protegidos de maneira plena.

A terceirização além de esvaziar a eficácia dos direitos fundamentais, ela reduz o padrão protetivo de emprego, conforme defende Lima (2010, p. 18):

O emprego rarefeito é aquele que, apesar da roupagem formal, mediante registro e observância esquemática de direitos trabalhistas, padece de déficit de efetividade normativa, por uma intensidade e por uma qualidade protetivamuito inferior ao padrãoconstitucionalmente assegurado às relações de emprego diretas,firmadas entre o obreiro eo tomador de serviços.

A CRFB/88 resguarda tanto o direito fundamental ao trabalho, quanto a garante constitucionalmente um trabalho digno. Nesse contexto, pondera Noêmia Porto (2013, p. 159):

As reflexões sobre a garantia constitucional do pleno emprego precisam se
vincular às demandas advindas das relações precárias ou rompidas com o
mundo assalariado. A plenitude não deve significar, de forma simplificada,
apenas a disponibilidade quantitativa de ocupações para as pessoas que
vivem do trabalho, mas sim a oferta de trabalho protegido, num contexto de
dignidade [...].

A terceirização, quando analisada apenas na lógica do mercado, de maneira ilimitada e sem a devida fiscalização impõe restrição às medidas de proteção dos direitos fundamentais dos trabalhadores. 
Voltando à análise da OIT, é de suma importância destacar que em 1998, ela introduziu o conceito de decentwork, que no português quer dizer como trabalho decente, ou o melhor entendimento como trabalho digno.

Os objetivos principais e estratégicos da OIT são: o respeito aos direitos do trabalho, principalmente relacionado à liberdade sindical e o direito de negociação coletiva; a eliminação de todas as formas de trabalho forçado; abolição do trabalho infantil; e por fim o extermínio de qualquer forma de discriminação em matéria de trabalho.

Diante disso, em 2003 o Brasil assumiu o compromisso e abraçou a ideia de Trabalho Decente perante a OIT.É com base nisso que o trabalho terceirizado e a normas que o regulamentam devem se inspirar. No compromisso de dar ao homem o que é seu por direito, buscando respaldo no princípio da dignidade da pessoa humana, na OIT e seus objetivos principais e por fim mas não menos importante, na legislação já existente.

O pensamento de Lopes (2003) pondera que "a construção de um projeto de vida, como auto realização pessoal, ínsito à dignidade da pessoa humana remete a um processo de luta, ou busca, por reconhecimento no amplo e complexo campo da sociedade, especialmente nos seus espaços de realização democrática”.

Sendo assim, considerando que a precarização das condições de trabalho causada pela relação terceirizante pode ensejar dano existencial ao trabalhador, é razoável afirmar que, há uma necessidade evidente de reformar a regulação sobre a terceirização, a fim de aumentar o âmbito de proteção do trabalhador terceirizado, bem como possibilitar a construção de sua identidade social a partir de seu reconhecimento.

Os prejuízos causados pela terceirização são numerosos, como as precariedades das condições de trabalho que aumentam os riscos de acidente de trabalho e possibilitam maiores índices de doenças ocupacionais. No mesmo sentido, tem-se a insegurança que novas empresas passam ao trabalhador.

\section{CONSIDERAÇÕES FINAIS}

Por séculos o trabalhador foi superexploradocom o intuito de proporcionar uma maior lucratividade às empresas. Nesse sentido, o indivíduo era submetido acondições desumanas e 
degradantes. Com o passar dos anos e com o cenário trabalhista prejudicado, surgiu o Direito do Trabalho com o objetivo de proporcionar ao trabalhador dignidade e direitos trabalhistas justos.

Porém, com a constante busca das empresas por redução de custos e aumento da lucratividade, aos poucos e de forma lenta, foi provocando o surgimento de uma nova modalidade de contratação, a terceirização. Esta não deve ser compreendida apenas como a desconcentração das atividades de uma empresa para um terceiro, mas também como uma forma de reorganização dos processos produtivos, podendo provocar danos aos trabalhadores terceirizados.

Ocorre que, na terceirização, não há um vinculo direto entre o trabalhador e a empresa tomadora de serviços, visto queesta apenas se utiliza da intermediária como forma de facilitar suas atividades, podendo focar somente nas atividades-fim, e como já dito, refletindo diretamente numa maior produtividade.

Nas relações de trabalho, o dano existencial decorre da conduta das empresas que impossibilitam que o trabalhador se relacione em sociedade. Dessa maneira, a terceirização acaba promovendo a redução de garantias constitucionais e aumentando a possibilidade de dano ao trabalhador.

Destaca-se, que a Lei n 13.439 de 2017 ampliou o rol de utilização da terceirização, admitindo que qualquer atividade da empresa possa terceirizar, retirando a restrição existente em relação ao exercício de atividade-fim que existia anteriormente.

Um grande malefício ao trabalhador são os enfraquecimentos dos sindicatos, fazendo com que perca benefícios conquistados pelo setor. É perceptível que numa visão empresarial e social, uma representatividade sindical tenha mais força e poder que um funcionário sem esse amparo e respaldo sindical.

A alta rotatividade aos terceirizados e a intermitência desses empregos prejudicam o contínuo levantamento de depósito do FGTS, reduzindo a capacidade de poupança do trabalhador terceirizado, além de reduzir o tempo de serviço proporcional do aviso prévio.

Por fim, o trabalho em condições desumanas vivenciado por muitos terceirizados prejudicam não só o meio de trabalho e sustento em si, masa vida e o convívio social do trabalhador.

Desse modo, é evidente o interesse das empresas de cada vez mais terceirizar os seus serviços e assim abaixar seus custos decorrentes da contratação de funcionários. Onde, 
enquanto de um lado defende-se que a terceirização é um avanço capaz de melhorar a situação econômica das empresas do país, do outro lado percebe-se a possibilidade de danos causados por essa contratação na vida dos trabalhadores.

A necessidade de fixação de limites constitucionais à terceirização se mostra imprescindível para a concretização dos direitos fundamentais ao trabalho digno, possibilitando a valorização do trabalho humano e a inclusão socioeconômica protegida do trabalhador.

É importante que emnosso atual cenário jurídico busque-se, com base na Constituição Federal e nas disposições daCLT, assegurar aos trabalhadores terceirizados condições dignas de trabalho e, assim, não permitir que os danos possíveis de existir se concretizem.

\section{REFERÊNCIAS}

ALVARENGA, Rúbia Zanotelly de. FILHO, Jorge Cavalcanti Boucinhas. O dano existencial e o direito do trabalho. Brasília: Rev. TST, vol.79 n², abr/jun 2013.

BARROS, Alice Monteiro de. Curso de direito do trabalho. São Paulo: Editora LTr, 5 ed. 2009.

BIAVASCHI, Magda Barros. COELHO, Elaine D’Ávila. DROPPA, Alisson. PERNÍAS, Tomás Rigoletto. O impacto de algumas (...). In: KHEIN, José Dari. GIMENEZ, Denis Maracci. SANTOS, Anselmo Luis dos. Dimensões críticas da reforma trabalhista no Brasil. Campinas, 2018, Cap. 7, p.213.

BIAVASCHI, Magda Barros. O direito do trabalho no Brasil - 1930-1942: construindo o sujeito de direitos trabalhistas. São Paulo: LTr, 2017.

BOMFIM, Vólia. Direito do trabalho. Rio de Janeiro: Forense, São Paulo: Método, $12^{\mathrm{a}}$ Ed, 2016.

BRASIL. Constituição da República Federativa do Brasil: Texto constitucional promulgado em 5 de outubro de 1988 - Brasília: Senado Federal, 2009.

BRASIL. Consolidação das Leis do Trabalho.

CASTRO, Rubens Ferreira de. A terceirização no direito do trabalho. São Paulo: Malheiros, 2000.

DELGADO, Maurício Godinho. Curso de Direito do Trabalho. São Paulo: LTr, $15^{\mathrm{a}}$ Ed, 2016. 
LIMA, Jacob Carlos. A terceirização e os trabalhadores: revisitando algumas questões. Cadernos de Psicologia Social do Trabalho, vol. 13, n. 1, p. 18, 2010.

LOPES, Othon de Azevedo. A dignidade da pessoa humana como princípio jurídico fundamental (...). Porto Alegre: Sínteses, 1ªed, 2003.

PAIXÃO, Cristiano. Terceirização: o trabalho como mercadoria. Distrito Federal: Sindjus, 2006.

PEREIRA, Ricardo José Macêdo de Britto. A Terceirização, a CLT e a Constituição. Blog Trabalho, Constituição e Cidadania. Disponível em: <http://trabalho-constituicaocidadania.blogspot.com.br/>. Acesso em: 05 de outubro de 2018.

PORTO, Noemia. O trabalho como categoria constitucional de inclusão. São Paulo: Editora LTr, Ed. 2013.

ROBORTELlA, Luiz Carlos Amorim. O moderno direito do trabalho. São Paulo: LTr, 1994.

ROMAR, Carla Teresa Martins. Direito do trabalho. (Coleção esquematizado) coordenador Pedro Lenza. 5. ed. São Paulo : Saraiva Educação, 2018.

SOARES, Flaviana Rampazzo. Responsabilidade civil por dano existencial. Porto Alegre: Livraria do Advogado, 2009.

SUSSEKIND, Arnaldo; MARANHÃO, Délio; VIANNA, Segadas; TEIXEIRA, Lima. Instituições de Direito do Trabalho. São Paulo: LTr, v.1, 2003.

VIANA, Márcio Túlio Viana; DELGADO, Gabriela Neves; AMORIM, Helder Santos. Terceirização - Aspectos gerais. A última decisão do STF e a Súmula 331 do TST.Novos enfoques. Rev. TST, Brasília, vol. 77, nº 1, jan/mar 2011.

VIANA,Márcio Túlio. Trabalhando sem medo: novas possibilidades para a protação ao emprego (...). In: SENA, Adriana Goulart de. DELGADO, Gabriela Neves. Nunes, Raquel Portugal. São Paulo: LTr, 2010. 